\title{
EDITORIAL
}

\section{Del fanatismo a la varidad del síntoma}

\author{
Juan Pablo Duarte*
}

\author{
Universidad Nacional de Córdoba
}

“Fanatismos ¿De qué lado estás?” es el título de la XIV edición del Ciclo de Cine y Psicoanálisis de la Universidad Nacional de Córdoba. El cine permite en esta edición trazar una cartografía en torno a figuras de dioses e ídolos cuyas fronteras están dadas en muchas ocasiones por la segregación en las múltiples formas que asume este fenómeno en la actualidad.

El film Hadewijch, del director francés Bruno Dumont (2009), es la vía de acceso escogida por Mariana Gómez para abordar el fanatismo religioso desde la noción de goce femenino. Hadewijch. Entre el misticismo y la pasión, el superyó es además el texto escogido para abrir el presente número del Journal Ética \& Cine. Para situar el modo en que un analista logra localizar al sujeto en alguien tomado por el fanatismo, Gómez rescata el caso de Marie de la Trinité, analizante de Jacques Lacan entre los años 1949 y 1953. La perfección con la que esta religiosa se imponía cumplir con sus deberes cifraría un padecimiento que permaneció incólume a más de veinte tratamientos psiquiátricos. La perfección marcó la vida de Marie, su fanatismo religioso y su angustia hasta que una interpretación acertada introdujo un equívoco: no se trata de perfección, se trata de obediencia ciega, de obedecer más allá de cualquier pedido.

Esta interpretación lacaniana podría inscribirse en el registro de la herejía. El hereje, por definición, se opone al dogma pero no intenta apartarse de quién cree él sino todo lo contrario. El origen de la palabra hereje, su etimología, se refiere a alguien que defiende la posibilidad de escoger lo que significa ese dogma. Se trata de una especie de ascetismo, el de alguien que cuestiona que las cosas tengan una significación última para sostener la posibilidad de escoger. En una palabra: el hereje está a favor de la posibilidad de elegir. Por este motivo, se resiste a ser expulsado o a despreciar aquello en lo que cree alguien o incluso la mayoría. Su gesto político se circunscribe a garantizar ese margen que existe entre las palabras y las cosas, entre las verdades y los hechos. El texto de Gómez también está tensado por una distancia, la que separa la Hadewijch de Dumont de Marie de la Trinité. Ambas mujeres lanzadas al encuentro con un Dios al que sacrificarse. Hadewijch lo encuentra, incluso más de una vez, Marie en cambio se encuentra con un hereje, el partenaire con el cual hacer de su fanatismo un síntoma.

El fanatismo, entendido como un arreglo con esa pequeña diferencia que habita la identidad, es el tema con el que Bárbara Navarro aborda el film Gilda, no me arrepiento de este amor de la directora argentina Lorena Muñoz (2016). El uso de la primera persona del singular es coherente con el desarrollo que plantea el texto. Navarro orienta su escrito desde su experiencia como analizante en relación a To be or not to be a fan. Un ídolo, un Dios o una santa, como de hecho es considerada Gilda, pueden ser muchas cosas. Una vía de escape a la partida que un sujeto debe jugar con la alteridad que lo habita, lo que habilita una posibilidad de lazo social -la comunidad de fanáticos- e incluso lo que brinde acceso al sentimiento oceánico de ser- Uno con el Todo al que se refirió Freud (1930) en El malestar en la cultura. Como muestra la experiencia que lleva adelante Juan Pablo Meneses con su religión portátil, un Dios y un ídolo pueden ser también objetos de consumo que se compran y venden. Antes de comprar un Dios en la India, este periodista chileno también compró un proyecto de ídolo, un niño futbolista. La compra y venta de un Dios, de un posible ídolo y hasta de una vaca, son los artilugios a partir de los cuales Meneses escribe la trilogía del periodismo cash, un género que nos permitirá conocer algunos pormenores de lo que, en el marco de la teoría psicoanalítica lacaniana, abordamos con la noción de discurso capitalista. Entonces ¿por qué no ser un fan? Por despertar, por encontrarse con el punto refractario a cualquier identificación que implica el

juanpduarte2@hotmail.com 
propio goce y dar lugar a la escritura de un síntoma singular.

La soledad es una de las condiciones de la escritura literaria y ésta una manera de separarse del pegoteo y la narcosis que implican las masas. Pero las obras pueden quedar relegadas del interés del público ante la fascinación por el autor de carne y hueso. Verónica Nieto, escritora nacida en Córdoba y afincada en Barcelona, autora de La camarera de Artand (2011), Kapatov o el deseo (2015) y Tangos en prosa (2014), aborda este tema a partir de El ciudadano ilustre, film argentino dirigido por Mariano Cohn y Gastón Duprat (2016). En un pasaje de su texto, La gente no quiere pensar, la gente quiere ser fan se puede leer la siguiente frase: "cuando se pone en juego la escritura, siempre se activa a su vez la primacía de lo tergiversado". Efectivamente, lo que Nieto refiere al plano de la literatura se puede trasladar al terreno del síntoma. En la clase del 19 de abril de 1977 del seminario L'insu que sait de l'une bérue s'aile a mourre, Lacan utiliza el neologismo "varidad" a modo de una propiedad del síntoma. Varidad condensa los términos vérité (verdad) yvariété (variedad) y expresa una dimensión variable de la verdad, puntualmente cuando esta se refiere al síntoma:

Sin eso, Freud hubiera extraído las consecuencias de lo que él mismo dijo -que el analizante no conoce su verdad puesto que no puede decirla. Lo que yo he definido como no cesando de escribirse, a saber el síntoma, es allí un obstáculo. A ello vuelvo -lo que el analizante dice, esperando verificarse, no es la verdad, es la varidad del síntoma. (Lacan, 1977)
El partenerato de las series de televisión con la subjetividad contemporánea, podría fundarse en la imposibilidad de decir la verdad acerca de lo real de diferentes síntomas sociales. Ariel Gómez Ponce aborda las series como un prisma de nuestra contemporaneidad. En "Instintos en serie", Ponce utiliza la serie irlandesa The Fall (RTÉ One, 2013-2016) como dispositivo para problematizar la noción de instinto en términos de una categoría semiótica. Esta operación de lectura le permite abordar los regímenes de poder a partir de los cuales la cultura contemporánea inscribe sentidos en diferentes planos de la subjetividad. En esta línea, Guess Who Coming to Dinner (Stanley Kramer, 1967) Mississippi Burning (Alan Parker, 1988) y The Help (Tate Taylor, 2011), tres films hollywoodenses que gozaron de un gran éxito comercial, permiten a Javier Cossalter abordar modalidades de segregación presentes en productos de gran impacto en la cultura masiva. Desde referencias teóricas y producciones culturales diferentes, La omnipotente blancura: el tratamiento de los Derechos Civiles en el cine norteamericano de Hollywood. Tres ejemplos paradigmáticos de éxito comercial e Instintos en serie introducen a diferentes dimensiones que el poder asume en la cultura. Las diferentes formas de representación del genocidio, tema abordado por Lior Zylberman, incorpora la perspectiva ética al análisis del género documental.

La literatura, el periodismo, el cine, las series de televisión y el documental, diferentes modos de hablar de nuestro tiempo que impulsan las teorías hacia nuevos territorios, esa es la matriz que impulsa a Fanatismos ¿de qué lado estás? al encuentro con sus lectores. 